\title{
The role of age and gender on implementing informal and non-formal science learning activities for children
}

\author{
Gabriella Tisza \\ Department of Industrial Design \\ Eindhoven University of \\ Technology \\ Eindhoven, The Netherlands \\ g.tisza@tue.nl \\ Netta Iivari \\ INTERACT Research Unit \\ University of Oulu \\ Oulu, Finland \\ netta.iivari@oulu.fi
}

\author{
Sofia Papavlasopoulou \\ Department of Computer Science \\ Norwegian University of Science \\ and Technology \\ Trondheim, Norway \\ spapav@ntnu.no
}

Michail N. Giannakos

Department of Computer Science

Norwegian University of Science and Technology

Trondheim, Norway

michailg@ntnu.no

\author{
Dimitra Christidou \\ Department of Computer Science \\ Norwegian University of Science \\ and Technology \\ Trondheim, Norway \\ dimitra.christidou@ntnu.no \\ Marianne Kinnula \\ INTERACT Research Unit \\ University of Oulu \\ Oulu, Finland \\ marianne.kinnula@oulu.fi
}

\author{
Iro Voulgari \\ Institute of Digital Games \\ University of Malta \\ Malta, Malta \\ iro.voulgari@um.edu.mt
}
Panos Markopoulos
Department of Industrial Design
Eindhoven University of
Technology
Eindhoven, The Netherlands
p.markopoulos@tue.nl

\begin{abstract}
There is a growing number of informal and non-formal learning activities worldwide related to STEM (Science, Technology, Engineering, Mathematics) subject areas - particularly, those related to coding and making. To understand the general aim and content of such activities, we conducted a survey addressing highly experienced instructional designers and instructors of informal and non-formal science learning activities in nine European countries $(\mathrm{N}=128)$. The goal of this paper is to investigate the relation between (1) the targeted age-group and (2) the gender of the participants in these activities, and (3) the gender of the activity leader experts and (I) the content and (II) the main goal of the activity. The results show that the gender and age of the participants and the gender of the activity leader experts are associated with regards to the underlined content and the goal of the activity. We introduce the revealed patterns that describe typical goals and content in association with the participant's gender and age along with patterns between the activity leader experts' gender and the content and the main goal of the activity. We discuss the study findings in detail, their implications and their value for the informal and non-formal learning communities.
\end{abstract}

\section{CCS CONCEPTS}

- Social and professional topics • Professional topics • Computing education $\cdot$ Informal education

\section{KEYWORDS}

Education, STEM, Coding, Making, Play, Science learning, Informal, Non-formal, Age, Gender

\footnotetext{
Permission to make digital or hard copies of part or all of this work for personal or classroom use is granted without fee provided that copies are not made or distributed for profit or commercial advantage and that copies bear this notice and the full citation on the first page. Copyrights for third-party components of this work must be honored. For all other uses, contact the Owner/Author.

FabLearn Europe '19, May 28-29, 2019, Oulu, Finland

(C) 2019 Copyright is held by the owner/author(s).

ACM ISBN 978-1-4503-6266-5/19/05.

https://doi.org/10.1145/3335055.3335065
}

\section{ACM Reference format:}

Gabriella Tisza, Sofia Papavlasopoulou, Dimitra Christidou, Iro Voulgari, Netta Iivari, Michail N. Giannakor, Marianne Kinnula, Panos Markopoulos. 2019. The role of age and gender on implementing informal and non-formal science learning activities for children. In Proceedings of ACM Fablearn Europe conference (FABLEARN EUROPE'19).

https://doi.org/10.1145/3335055.3335065

\section{Introduction}

Nowadays, the contribution of informal and non-formal learning activities to lifelong learning is widely acknowledged with the concepts of ubiquitous, everyday and intuitive learning drawing the attention of both educational institutions and society (e.g. $[12,26])$. Despite the increasing interest, informal and non-formal activities are still not well understood while most of their design decision relying on the intuition of the expert or the instructional designer. Informal and non-formal science learning activities for children occur in different places and contexts, such as museums, libraries, computer clubs, Fab Labs, youth centres, conferences, or universities (e.g. [3-6, 8, 9, 14, 17, 21, 28, 30, 31, 36]). Some studies report on entirely voluntary making activities, taking place in youth centres, museums, libraries or computer clubs, whereas other studies explore activities organized as elective, after-school classes, or extra-curricular activities or even as summer-camps (e.g. $[5,9,31])$. From the wide range of places and contexts, much attention has been given to activities taking place in a more traditional environment (i.e. museums, zoos, exhibitions etc.). While the links and contributions of the emerging innovative, creative learning and digital fabrication spaces - where the elements of fun and playfulness are dominant and the activities are constituted from diverse coding and making activities - to science education are still underexplored. Although most of the informal and non-formal activities are focused on STEM (Science Technology, Engineering, Mathematics), we have seen a wide diversity of design decisions and no clear rationale relating the expected learning outcomes and the way the activity is designed $[15,18]$. Two of the most important elements emphasized in the literature [27] are the age and gender of the participants. However, there are no clear guidelines on how such differences can be addressed during the design of the activity.

To find out whether there is an underlying pattern that influences the content and goals of informal and non-formal science learning 
activities, we conducted a survey study focusing on coding, making, and playful activities, in nine European countries (Austria, Finland, Greece, Malta, Netherlands, Norway, Spain, Sweden, Uk). In this paper, we examine responses from 128 highly experienced instructional designers and instructors of informal and non-formal science learning activities (i.e. experts) to explore how the targeted age-group and gender of the participants and the experts' gender relates to the content and goals of the activity.

The novelty of our study is that it is the first research of its kind in terms of content and extent. While there are other studies available on non-formal and informal science learning, our research is one of the first to be conducted in such an overarching way at a European level. Hence, the dynamics and associations between the target age group, gender and content have not been studied before. Gaining insight into these dynamics not only increases our understanding on the ongoing non-formal and informal science learning activities in general, but also provides a good starting point to design future activities in a more conscious way; for example, to fill existing gaps, to increase girls' involvement, or to design activities that better suit the anticipated audience. In this paper, we discuss how our findings can inform future science learning activities, as well as to advance research in the area of informal and non-formal science learning activities for children.

\section{Theoretical background}

\subsection{Formal, Informal and Non-Formal Learning}

Before presenting our study, it is important to introduce our conceptualization of informal and non-formal learning and address the main differences between those and formal learning. For our conceptualization, we draw upon the definitions of The Council of Europe ${ }^{1}$ and those provided by Eshach [11]. In this light, formal learning happens usually at school and it is often repressive, structured, prearranged and sequential. Formal learning is led by a teacher, who evaluates the learning outcomes, and students' motivation is extrinsic as their participation is compulsory. Nonformal learning, on the other hand, happens usually outside the school, and it is supportive and non-sequential, with the activity being guided or teacher-led. The learning outcome is usually not evaluated and students' motivation is typically more intrinsic as their participation is mostly voluntary. Lastly, informal learning is supportive, unstructured, and spontaneous. The leaning activity is learner-led and non-sequential, the learning is not evaluated and the motivation for participation is mainly intrinsic and therefore voluntary. An overview of the main differences between the three terms based on the definitions of the Council of Europe and Eshach [11] is presented in Table 1 .

\begin{tabular}{ccc}
\hline Formal & Non-formal & Informal \\
\hline $\begin{array}{c}\text { at formal learning } \\
\text { space }\end{array}$ & $\begin{array}{c}\text { outside of formal } \\
\text { learning } \\
\text { environment }\end{array}$ & everywhere \\
follows a syllabus & $\begin{array}{c}\text { might follow a } \\
\text { syllabus }\end{array}$ & $\begin{array}{c}\text { doesn't follow a } \\
\text { syllabus }\end{array}$ \\
structured & structured & unstructured \\
compulsory & usually voluntary & voluntary \\
\hline
\end{tabular}

\begin{tabular}{ccc}
\hline $\begin{array}{c}\text { extrinsic } \\
\text { motivation }\end{array}$ & $\begin{array}{c}\text { typically intrinsic } \\
\text { motivation }\end{array}$ & $\begin{array}{c}\text { intrinsic } \\
\text { motivation }\end{array}$ \\
$\begin{array}{c}\text { learning goals are } \\
\text { predetermined by } \\
\text { the educator }\end{array}$ & $\begin{array}{c}\text { learning goals arise } \\
\text { from the learners’ } \\
\text { conscious decision }\end{array}$ & no learning \\
$\begin{array}{c}\text { learning outcomes in mind } \\
\text { are measured }\end{array}$ & no assessment & no assessment \\
\hline
\end{tabular}

Table 1. Differences between formal, non-formal and informal learning

\subsection{Related Work}

With the bulk of literature reporting on specific cases and design research studies, there are only a few studies that have examined the content and main goal of informal and non-formal learning activities in STEM at an overarching, comprehensive level. The study of Falk and colleagues [12] examined the UK science education by taking a systemic perspective. They examined science learning as a whole by including both formal and the non-formal settings and they sought to collect information regarding, among others, the educational goals and target audiences of such activities. In their exploratory research, they collected nation-wide information on science education from 169 science educators from across the UK with a web-based questionnaire. Their findings suggest some consistency in the distribution of audiences across sectors: a predominant focus on children and youth (age range of 5-19), followed by adult audiences. Regarding the educational goals of such activities, the most frequently mentioned were to make science enjoyable and interesting (91\%) and inspire a general interest in and engagement with science (89\%), whereas the least frequently mentioned were preparing participants for further science education or careers $(27 \%)$, encourage further learning in non-science subjects $(23 \%)$ and prepare participants for non-science careers (12\%).

Similar tendencies regarding the target audience and the goal of the activities is expected to be mirrored at a European level. However, our study goes beyond the study of Falk and colleagues [12] as we not only investigate the target audience and the goal of the activities, but the association between the target audience (age and gender), the gender of the experts, and the goal and the content of the activity.

\subsection{The Role of Age and Gender}

Gender differences regarding children's interest in STEM fields is a growing concern for researchers in both academia and industry [10]. Activities involving coding and making have been proven to be highly gendered and many assumptions, biases, and misbeliefs may influence children's participation (e.g. [9, 17, 25]). The gender similarities hypothesis [16] suggests that the apparent differences in motivation, attitudes and achievement between boys and girls towards STEM subjects are developed over time and are not genetically inherent to their gender.

Growing empirical evidence suggests that these differences originate from the socio-cultural features of the learning context [38]; for example, the teachers' gender may affect students' participation and performance in science and engineering [35]. Doerschuk and colleagues [7] found that the gender gap between

\footnotetext{
${ }_{1}$ https://www.coe.int/en/web/lang-migrants/formal-non-formal-and-informal-learning
} 
boys and girls interested in computer science could be already identified at early secondary school age ( $\sim 11$ years-old). Additionally, a study by Microsoft [37] involving 11,500 girls from twelve European countries suggested that girls' interest toward STEM subjects starts to decrease around age 12 , and only starts to increase again around age 20 when their career direction has already been determined. The underlying factors for the decreased interest in STEM fields among girls include having no available role model and not getting enough practical, hands-on experience with STEM subjects [37]. Other studies suggest that females' interest in scientific fields dominated by males is associated with females' self-confidence in their relating abilities, which is significantly supported by early-age possibilities to engage with scientific activities [38]. Thus, engaging girls from early ages with science across informal and non-formal science learning activities might provide the necessary support for developing and sustaining interest toward the STEM fields.

Our study investigates the age group of the target audience of science learning informal and non-formal activities to understand whether early engagement of girls is present in our dataset from the nine countries. Additionally, we study girls' participation in the informal and non-formal science learning settings to see whether the decreased interest is present and whether girls' participation can be associated with the content or the goal of the activity. Moreover, we investigate the gender distribution of the experts in order to assess whether an available role model for both genders is present.

\subsection{Intrinsic Motivation}

Intrinsic motivation is "the inherent tendency to seek out novelty and challenges, to extend and exercise one's capacities, to explore, and to learn." ([32] p. 70). Developmental psychologists acknowledge that children are especially and generally driven by intrinsic motivation during their physical and mental development. However, certain social-contextual conditions are needed to trigger intrinsic motivation. According to Malone and Lepper [23, 24], intrinsic motivation can be evoked by optimal levels of challenge, curiosity and fantasy. Based on the cognitive evaluation theory [33], as long as the psychological need for feeling competent is present, positively challenging activities that promote greater perceived competence can evoke intrinsic motivation because they satisfy the individual's need for feeling competent. Additionally, in contrast to formal learning activities, extracurricular - thus informal and non-formal - activities have been associated with an increased level of engagement and intrinsic motivation among adolescents [22]. Intrinsic motivation, therefore, is considered to have a strong effect on learning in general, and to play a key role in case of informal and non-formal science learning activities.

\subsection{Engagement}

Engagement is generally categorized into three facets: behavioural, emotional and cognitive engagement [13]. In educational studies often each of them is investigated. "Behavioral engagement refers to effort and persistence and (...) the emphasis is on the amount or quantity of engagement (...). In contrast, cognitive engagement refers to the quality of one's thinking in terms of cognitive strategies (e.g., elaboration, rehearsal), metacognitive strategy use, and self-regulated learning." ([20] p. 113). Affective engagement refers to the emotional facet of engagement: students' eagerness, interest, enjoyment and enthusiasm are frequently taken as major indicators [19]. Based on Bandura's Social Cognitive Theory [2], learner's affective and cognitive engagement is constructed through continuous interaction with the learning environment. Additionally, an activity is optimally engaging, when the level of skills and challenge are met: then a higher quality of perceived engagement, intrinsic motivation, mood and self-esteem is present [34]. Informal and non-formal science learning activities - as it was pointed out for example by the study of Falk and colleagues [12] are strongly focused on getting participants engaged, especially at the affective level. Hence, in the current study, we investigate the goal of the activities and the possible impact of those on the participants' intrinsic motivation and engagement.

\subsection{Research Questions and Hypotheses}

In this study, besides investigating the target audience, the goal and the content of the ongoing informal and non-formal science learning activities across Europe, we set out to answer the following research question: How is the age-group and the gender of the participants, and the experts' gender related to the content and aims of the activity? We expected that (a) at younger ages the focus of the activity is more on raising awareness and engagement, while in older children it is more about improving skills; (b) the activities that are designed for and/or more frequently visited by boys are more likely to cover physics, chemistry, mathematics and computer science, while the activities that are designed for and/or more frequently visited by girls are more likely to cover biology, humanities, literature and arts; and (c) the gender of the experts has an effect on the goal of the activities and the curricular subjects covered.

\section{Methods}

To address the research question, we carried out a survey study that targeted leaders/practitioners of ongoing informal and non-formal science learning activities across Europe. We followed an intensity sampling approach ("information-rich cases that manifest the phenomenon intensely, but not extremely" [29] p. 182), and collected responses from 128 highly experienced instructional designers and instructors (i.e. experts) of informal and non-formal science learning activities from the aforementioned nine European countries, each representing a country in which members of the research team are active. The inclusion criteria for the activities were the following three: (i) to be an informal or non-formal science learning activity, (ii) to be playful and, (iii) to involve either coding or making. The activity leader experts were identified through desk research which collected information about the ongoing non-formal and informal science learning activities in each country available online. The experts were recruited electronically through e-mail or were personally approached and invited to participate in the study.

\subsection{Development of the Survey}

In order to design our survey, we firstly investigated the nature of informal and non-formal science learning activities across the existing literature and established several dimensions along which the activities had been in general evaluated. These dimensions are (i) the learning objectives, (ii) the link to science education, (iii) the participants (age, gender), (iv) the duration of the activity, (v) the learning methods, (vi) the context and (vii) the formality of the setting. These dimensions served as the backbone of the survey which was then fed with questions/statements assessing these established dimensions. Thereafter, the main structure and the content of the survey were discussed and improved in several iterations with a group of experts which consisted of informal and non-formal science learning practitioners and field researchers. The survey consisted of 35 questions, seven of which concerned demographic information. From the remaining 28 questions, which investigated the ongoing activities, 10 were open-ended. The 
language of the survey was English, however, responses for the open-ended questions could be given in the native languages of the respondents. The final version of the survey was digitized and shared through an online link securing free anonymous access.

\subsection{Data Collection}

The survey was active in October and November 2018 during which time we collected responses from 128 experts. For the data collection, we applied an intensity sampling approach, where we reached out for highly experienced instructional designers and instructors having a general profile on informal or non-formal science learning activities.

\subsection{Data Analysis}

Simple frequency analysis was applied for the descriptive statistics. To investigate the effect of age-group and gender on the subjectareas and goals of the activity, we employed Pearson's Chi-squared $\left(\chi^{2}\right)$ test, with age-group and gender (both children and instructors) as the three independent variables and the subject-areas and goal of the activity as dependent. For the data analysis, the IBM SPSS Statistics v25 software was used.

\section{Results}

\subsection{Demographics of the Experts}

The response rate per country cross-classified by gender $(\mathrm{N}=128)$ is presented in Table 2 . In three of the cases, the country indication was either missing or marked as 'other'.

\begin{tabular}{lcccc}
\hline & Female & Male & $\begin{array}{c}\text { Prefer not to } \\
\text { say / other }\end{array}$ & Total \\
\hline Austria & $4.7 \%$ & $7.0 \%$ & $1.6 \%$ & $13.3 \%$ \\
Finland & $5.5 \%$ & $9.4 \%$ & $0.8 \%$ & $15.6 \%$ \\
Greece & $4.7 \%$ & $4.7 \%$ & $1.6 \%$ & $10.9 \%$ \\
Malta & $3.1 \%$ & $2.3 \%$ & $0.0 \%$ & $5.5 \%$ \\
Netherlands & $1.6 \%$ & $3.9 \%$ & $0.0 \%$ & $5.5 \%$ \\
Norway & $3.1 \%$ & $11.7 \%$ & $0.0 \%$ & $14.8 \%$ \\
Spain & $7.8 \%$ & $7.0 \%$ & $0.0 \%$ & $14.8 \%$ \\
Sweden & $2.3 \%$ & $3.9 \%$ & $0.0 \%$ & $6.3 \%$ \\
UK & $5.5 \%$ & $5.5 \%$ & $0.0 \%$ & $10.9 \%$ \\
Missing/other & $1.6 \%$ & $0.8 \%$ & $0.0 \%$ & $2.3 \%$ \\
Total & $39.8 \%$ & $56.3 \%$ & $3.9 \%$ & 100.0 \\
& & & & $\%$ \\
\hline
\end{tabular}

Table 2. Proportional table of respondents per country by gender $(\mathbf{N}=128)$.

The gender distribution of males and females is $56.3 \%$ and $39.8 \%$ respectively. Regarding the occupation of our respondents, $77.3 \%$ do the science learning activities as a normal job, while $21.1 \%$ of them are volunteers. Additionally, $76.6 \%$ of the respondents belong to an organization, while $19.5 \%$ are working independently.
The average time spent on the activities per week varied from 0 to 60 hours; however, $21.9 \%$ of the respondents could not specify a fixed weekly basis either because the average time spent on the activities varied a lot or because it is a project that occurs within a certain period of time. From the respondents who could estimate their average weekly hours spent on the activities, 56\% work a maximum of 10 hours on the activities, $16 \%$ of them work between 10 and 20 hours, $6 \%$ of them works between 20 and 30 hours, $16 \%$ of them work in full-time (35 to 40 hours) and only $4 \%$ of the respondents spend more than 40 hours a week on the activities.

\subsection{Target Audience of the Activities}

As aforementioned, the survey sought to collect data on the target audience of the activities represented in the survey. For this question, respondents were given four options, from which they were allowed to select more than one. Based on the responses, we can conclude that the activities target all age-groups, but in an uneven distribution. The least targeted age group was the nurseryaged pupils (age 4-6; 18\%) followed by young adults (higher education, age $17 / 18-21 ; 25 \%$ ), secondary school students (age 13$17 / 18 ; 60.2 \%$ ) and primary school students (age 7-12; 74.2\%).

Given the general gender inequality identified in scientific fields (section 2.3), we were interested in whether the same tendency could be identified in informal and non-formal environments. Therefore, the survey asked the experts to estimate the average gender proportion of the participants in their activities. For this question, our valid cases were $\mathrm{N}=120$, since in 2 cases the experts reported that they didn't have any relevant data and in 6 cases they didn't respond. We coded the responses into the following four categories: i) less than $45 \%$ of the participants are girls (i.e. girls are the minority); ii) $45 \%-55 \%$ of the participants are girls (i.e.approximate gender balance); iii) more than $55 \%$ of the participants are girls (i.e. girls are the majority); and iv) it depends. Out of the 120 participants, $45.8 \%$ estimated less than $45 \%$ girls participate in their activities, $36.7 \%$ of the respondents reported approximately $45 \%-55 \%$ girls, and $10.8 \%$ reported more than $55 \%$ girls, and $6.7 \%$ responded that it depends on various factors. In other words, in roughly half of the studied cases, boys are the majority during the activities. However, participation is only dominated by girls at approximately $10 \%$ of the studied activities.

\subsection{Content and Main Goals of the Activities}

As it was indicated previously, the study had a special interest in coding, making and play activities. The coverage of these topics was assessed by a question where experts could select multiple responses. The options and the concerning selection rate were as follows: $65.6 \%$ of the surveyed experts report the use of computers during the activity, $62.2 \%$ of the activities are intended to be playful, $61.7 \%$ of them involves making, $52.3 \%$ involves coding and $39.1 \%$ involves games.

In order to explore the main goal of the activities, we provided the respondents with five options that aligned with the framework of the National Science Foundation for evaluating the impact of informal science education projects [1]. In this case, only one option could be selected among the following five: a) Attitude (change in attitude toward a particular scientific topic, concept, phenomena, theory, or careers central to the project or one's capabilities relative to these areas.); b) Awareness, knowledge or understanding (change in awareness, knowledge, understanding of a particular scientific topic, concept, phenomena, theory, or careers central to the project); c) Engagement or interest (change in engagement/interest in a particular scientific topic, concept, phenomena, theory, or careers central to the project); d) Skills 
(Development and/or reinforcement of skills, either entirely new ones or the reinforcement, even practice, of developing skills (e.g. using microscopes or telescopes successfully); and e) Behaviour (change in behaviour related to the topic). The analysis of the responses revealed that the $35.9 \%$ of the experts aim the activity to increase engagement, $28.3 \%$ aims to increase awareness, $22.7 \%$ aims to improve skills, $7 \%$ focuses on attitude- and $0.8 \%$ on behaviour change.

To explore how the studied informal and non-formal learning activities relate to the formal learning, we examined their learning goals and intentional curriculum material coverage. We asked the experts across yes/no questions whether the activity is designed to help participants to attain qualifications, whether the activity has (some) explicitly expressed learning goals, and whether those learning goals are explicitly linked to school curricula. The proportion of the yes responses were $33.6 \%, 52.6 \%$ and $35.2 \%$ accordingly.

Regarding the covered curricular subjects, we provided the respondents with a list of eleven subjects, from which they could choose more than one. Based on the indication of the experts technology (68\%), computer science $(50.8 \%)$, physics $(47.7 \%)$, mathematics (46.1\%), design (46.1\%) and arts (39.1\%) are the most favored ones followed by biology (25.8\%), chemistry (25\%), geography (15.6\%), humanities (14.1\%) and literature (8.6\%).

Concerning the educational design of the studied activities, experts were asked to indicate up to three from the nine predetermined options that describe the best what happens during the activity. In this case, the terms were not defined as we expected that the surveyed experts were familiar with the meaning of the terms in case they applied those during their activities. Experts indicated that they most frequently applied in their activities creative thinking (59.4\%), project or task-based learning $(53.9 \%)$, collaborativelearning (48.4\%), discovery-learning (46.1\%), and problem-based learning $(41.1 \%)$. The least frequently indicated options were design-based learning (28.9\%), critical-thinking (28.1\%), real-life challenges $(24.2 \%)$ and the involvement of families/communities $(21.9 \%)$.

\subsection{The Effect of Participants Age Group in the Subject Areas and Goals of the Activities}

Experts could make multiple choices to indicate the age-group of their target audience, as they might be addressing different groups in their work. Responses were analyzed to assess whether children's age can be associated with the aim of the activity and the covered curricular subjects, with a Pearson's Chi-squared test $\left(\chi^{2}\right.$, $\mathrm{N}=128$ ).

With respect to the effect of the age on the aim of the activity, there was no association found neither for nursery-aged children $\left(\right.$ Cramer's $\left.\mathrm{V}=0.101, \chi^{2}(5)=1.295, \mathrm{p}=0.935\right)$, nor for primaryaged children (Cramer's $\mathrm{V}=0.170, \chi^{2}(5)=3.683, \mathrm{p}=0.596$ ) nor for secondary-aged children (Cramer's V $=0.164, \chi^{2}(5)=3.4375$, $p$ $=0.633)$. However, there was a significant difference between the goal of the activities for young adults (age 17/18-21; Cramer's V = $\left.0.322, \chi^{2}(5)=13.280, p=0.021\right)$. Namely, raising awareness (Cramer's V $=0.253, \chi^{2}(1)=8.193, p=0.004$ ) was positively and significantly $(\mathrm{p}<0.05)$ associated with this age-group. However, engagement was found to be negatively associated (Cramer's $\mathrm{V}=$ $\left.0.169, \chi^{2}(1)=3.665, \mathrm{p}=0.056\right)$.

When assessing the relationship between the age-groups and the covered curricular subjects, we found a significant positive association between nursery-aged children and biology (Cramer's
$\left.\mathrm{V}=0.189, \chi^{2}(1)=4.589, \mathrm{p}=0.032\right)$, positive association with chemistry (Cramer's V $=0.153, \chi^{2}(1)=2.986, p=0.084$ ) and literature (Cramer's $\mathrm{V}=0.147, \chi^{2}(1)=2.763, \mathrm{p}=0.096$ ), and a negative association with computer science (Cramer's $\mathrm{V}=0.150$, $\left.\chi^{2}(1)=2.871, p=0.090\right)$. Additionally, we found a positive association between young adults (age 17/18-21) and physics (Cramer's V $\left.=0.172, \chi^{2}(1)=3.769, \mathrm{p}=0.052\right)$. Regarding the other age-groups (primary and secondary education), no association was found.

\subsection{The Effect of the Gender of Participants in the Activities}

We also examined whether the percentage of boys/girls is related to the goal of the activities and to the curricular subjects covered by the activity. As described in section 4.2, the respondents of the survey were asked to estimate the percentage of girls participating in their activities. Consequently, we coded their responses into four categories: (i) $<45 \%$ girls, (ii) $45 \%-55 \%$ girls, (iii) $>55 \%$ girls, and (iv) it depends for the cases where no fixed number was given but it was instead reported that it depends on the age-group, the topic or theme of the activity, or the venue.

We examined the association of these categories with the main goal and the curricular subject of the activities, as reported by the experts. Here again, Chi-squared independence tests were used for examining their association. Regarding the participation of girls in relation to the covered curricular subject of the activity, a statistically significant association was observed for the following subjects: computer science (Cramer's V $=0.364, \chi^{2}(3)=15.88, \mathrm{p}=$ 0.001 ), physics (Cramer's V $=0.261, \chi^{2}(3)=8.18, \mathrm{p}=0.042$, chemistry (Cramer's $\mathrm{V}=0.301, \chi^{2}(3)=10.88, \mathrm{p}=0.012$ ), biology (Cramer's V $=0.445, \chi^{2}(3)=23.74, \mathrm{p}=0.001$ ), and arts (Cramer's $\left.\mathrm{V}=0.285, \chi^{2}(3)=9.73, \mathrm{p}=0.021\right)$. In the cases of arts, biology, chemistry, and physics the percentages of boys and girls were mostly equal ( $45 \%$ - 55\%), while in the case of computer science, the percentage of boys participating was in most of the cases higher

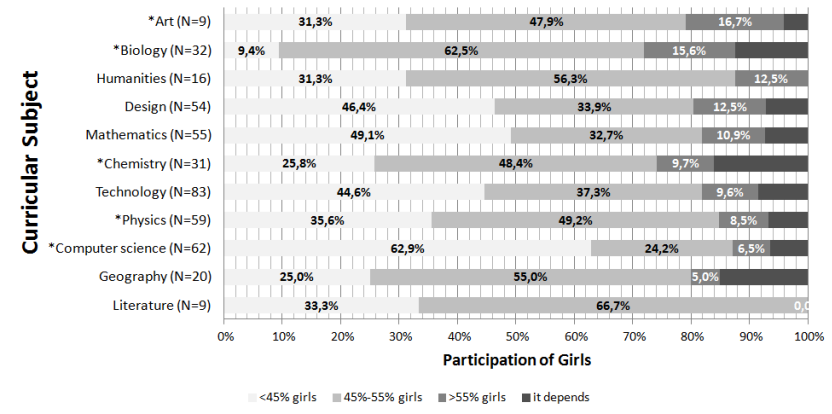

than the percentage of girls (Figure 1).

Figure 1. The interaction between the participants' gender and the covered curricular subjects

We found no significant association between the percentage of girls participating in the activity and the main goal of the activity. Nevertheless, the lowest participation of girls is observed in activities where skills improvement was reported as the main goal; $63 \%$ of the experts who reported skills as the main goal of the activity estimated a percentage of less than $45 \%$ female participants. The highest participation of girls was reported in the cases where the main goal was engagement. $16 \%$ of the respondents for this activity aim (engagement) also reported a percentage of more than $55 \%$ of girls in those activities. Equal representation of girls and boys was reported for activities where the main goal was change in attitude with $55.6 \%$ of the respondents selecting attitude 
as their main activity aim, reporting a percentage of participation of girls between $45 \%$ and $55 \%$ (Figure 2).

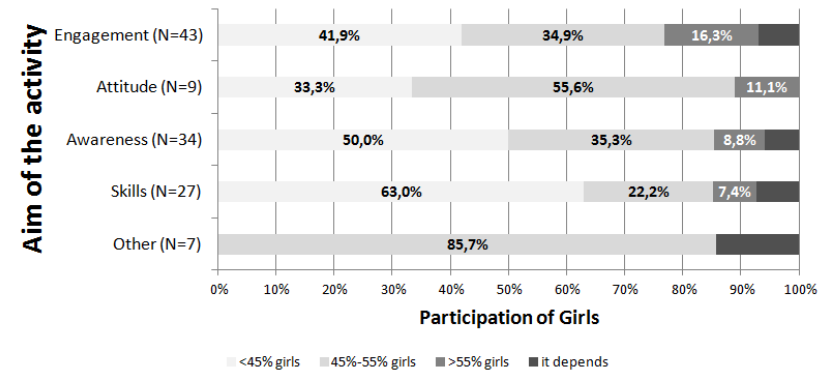

Figure 2. The interaction between the participants' gender and the main goal of the activity

\subsection{The Effect of the Gender of the Experts}

We examined whether the gender of the experts can be associated with the main goal and the covered curricular subject of the activities $(\mathrm{N}=128)$. For the experts' gender, we offered four options: male, female, other and prefer not to say. For examining the association of the variables, here again, Chi-squared independence test was used which indicated no significant association between the gender of the experts and the main goal of the activity. In most of the cases, the experts were mainly males except for the cases where the aim of the activity was attitude change. There seemed to be an equal representation of male and female experts (thus compared to the sample distribution females were overrepresented) and the cases of awareness, where $47 \%$ were male experts, $38 \%$ were female, and $14,7 \%$ other or preferred not to say. Behaviour change as the main goal of the activity was selected by one participant who was female (Figure 3).

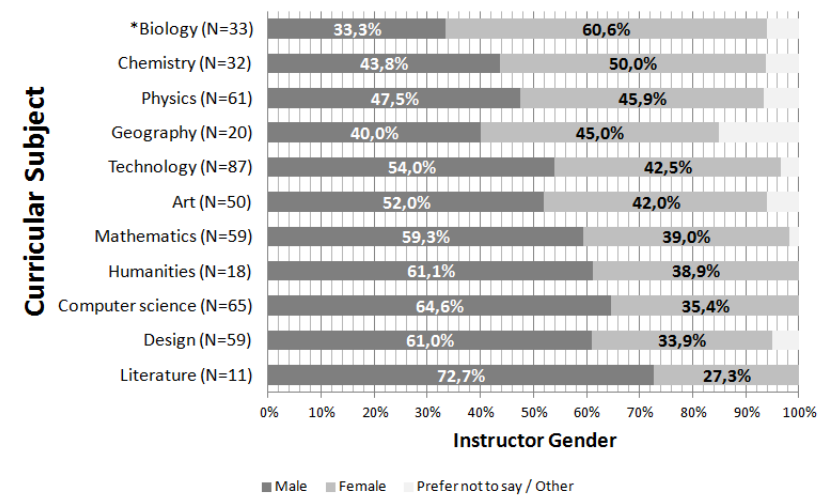

Figure 3. The interaction between the experts' gender and the covered curricular subjects

We also found no significant association between the gender of the expert and the covered curricular subject of the activity, except for the case of biology (Cramer's $V=0.275, \chi^{2}(3)=9.66, p=0.022$ ) where most of the experts were female $(60.6 \%)$. Also, most of the experts were female, with no significant difference though, in the cases of chemistry and geography. Most of the females in our sample (55\%) selected physics as the covered curricular subject of their activities, while most of the males selected technology (65\%) (Figure 4).

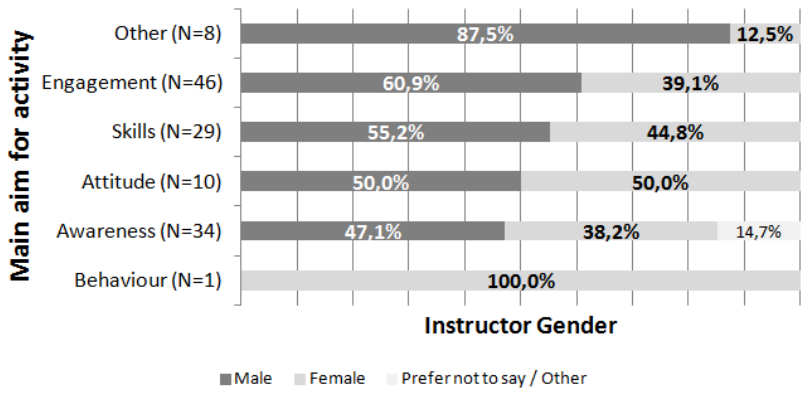

Figure 4: The interaction between the activity leader experts' gender and the main goal of the activity

\section{Discussion}

We presented a survey study of informal and non-formal science learning activities across Europe. The aim of the study was twofold: (1) to map the currently ongoing activities and gain an overview of these, and (2) to find out whether there are underlying patterns in association with the content and goal of these activities. We collected survey data from 128 highly experienced instructional designers and instructors (i.e. experts) of informal and non-formal science learning activities from nine European countries. Our results illustrate how the currently ongoing informal and nonformal science learning activities have a very vivid and broad range of variety in terms of their main goal, content, and target audience.

Regarding the profile of the experts, we found that more males than females work on the activities, and the experts mostly work as employees of an organization in a part-time job. Perhaps the latter is an indication that such learning activities are still not yet mainstream and thus, our surveyed experts run them rather as their hobby, driven by personal motivations. This might explain as well why each fifth of the surveyed experts is self-employed.

The main target audience of the activities led by the surveyed experts is either the 7-12 years age-group and/or the 13-17/18 years age-group, a finding that complies with the one reported by Falk and colleagues [12]. Our research results differ in the sense that we found very limited coverage for nursery-aged children (age 4-6), while the coverage for young adults (age 17/18-21) was moderate. Our findings suggest that girls are generally under-represented in the surveyed activities. In approximately half of the cases, boys are estimated as the majority, compared to $10 \%$ of the activities where girls are the majority. However, about one-third of the activities are gender balanced.

As for the actual content of the activities, almost two-thirds of them involve making and approximately half of them involve coding. Approximately one-third of the activities aim to help participants to attain some kind of qualification, half of them have explicit learning goals, and those goals are explicitly linked to the school curricula in approximately one-third of the cases. Highlighting the link even further between the formal and informal/non-formal learning, the majority of the studied activities cover the formal educational subjects of technology, computer science, physics and mathematics.

Based on the responses, we can conclude that the main goals of the activities are to increase engagement and awareness, and to improve skills - a finding that aligns with the goals reported by Falk and colleagues [12]. It is important to note that two-thirds of the activities are intended to be playful. Thus, the general goal of the 
activities is encouraging young people in a playful way to become interested in scientific topics, to get them engaged and to improve their related skills.

The novelty of the current research (on both national and European level) is the investigation of the relation between the age group and the gender of the participants, and the gender of the experts, and the goal and the content of the activities. It appears that the participants' age can be associated with both the goal and the content of the activities. We found that for young adults (age 17/18-21) raising awareness was the main goal of the activity, whereas no specific goal was found for the other age-groups. These findings are unexpected, as our hypothesis was that at younger ages the focus of the activity is more on raising awareness and engagement, while in older children it on more about improving skills. Regarding the covered formal educational subjects, for nursery-aged children (age 4-6) biology, chemistry and literature were positively, and computer science was negatively associated while for young adults (age 17/18-21) physics was positively associated.

Regarding the effect of the participants' gender, we can conclude that gender is associated with both the goal and the content of the activities. As for the goal of the activities, the lowest participation of girls was found in activities where the goal was skills improvement, and the highest participation of girls was found where the main goal of the activity was to increase participants' engagement with scientific topics. A possible explanation could be that some of these activities aim to encourage higher participation of women in STEM-related education. With respect to the covered curricular subjects, we found that when arts, biology, chemistry and physics were covered, the gender distribution of the participants was approximately equal. However, in the case of computer science, boys were overrepresented. These results are in accordance with data collections about STEM education and degrees in the US [39], especially with regards to biology, which is known to be the only gender balanced STEM field. In addition, those results reflect partially on our hypotheses - that the activities that are designed for or more frequently visited by boys are more likely to cover physics, chemistry, mathematics and computer science, while the activities that are designed for or more frequently visited by girls are more likely to cover biology, humanities, literature and arts.

Apparently, the gender of the experts can be associated with specific goals and covered curricular subjects. It is important to note that male experts were overrepresented in our sample. This may be studied further to understand whether there is a general tendency or due to a sampling bias. Regarding the goal of the activity, no significant association was found. In most cases, the experts were mainly males however, in case of aiming for an attitude change, females were overrepresented compared to the sample distribution. With regards to the covered curricular subjects, a significant association was found between females and biology, and the majority of the experts of activities covering chemistry and geography were also females. Additionally, the most commonly covered subject by male experts was technology while the most commonly covered curricular subject among females was physics. These results are also in accordance with the aforementioned US study [39], with special regards to the significant association between woman and biology. Our findings support that this phenomenon has its roots in early childhood as biology was found to be significantly related to nursery-aged children, while an approximately equal number of girls and boys are found to be present overall in the activities that cover the subject. Regarding our hypotheses, we can conclude that the gender of the experts is in association with the goal of the activities and the covered curricular subjects, however, this association is proposed to be further studied.
Evaluating our research findings from the perspective of the theories introduced in the Theoretical background section with regards to engagement (section 2.5) and motivation (section 2.4), it can be concluded, that the herein studied activities contribute to evoking young Europeans' interest towards scientific topics. The studied activities are mainly intended to be playful and engaging at both the affective, behavioural and cognitive level. Thus, they aim at triggering young people's curiosity and intrinsic motivation that enhance their willingness to learn about science. Additionally, young people are often able to take home their creations/artefacts, which adds up to the whole experience and functions as a reminder that learning science is fun. Although girls are generally underrepresented in the studied activities, our findings are promising as we found approximate gender balance at more than one-third of the activities. Additionally, having approximately $40 \%$ of females among the experts can provide girls with the muchneeded role model pointed out by the Microsoft study [37].

\section{Conclusion}

In sum, our study contributes to the existing literature in the following ways: a) we have provided a general overview of the content, goal and target age-group of informal and non-formal science learning activities, and information as well with respect to the leaders of such activities based on responses from 128 experts from nine European countries; and b) we shed light on associations between the participants' age and gender and the experts' gender and the content and goals of the activities.

Based on our findings we can conclude that 1) the participants' gender and age are in association with the goal and the content of the activity; and 2) the activity leaders' gender is in association with the content and the goal of the activity.

In other words, there is a difference between the activities that girls are more frequently participating in and those activities in which boys are more frequently participating. Girls are more frequently found at activities aiming at engaging participants with various scientific topics, and the covered curricular subjects are arts, biology chemistry and physics. Boys, on the other hand, are more frequently found at activities where the goal of the activity was skills improvement and it covered the curricular subject computer science.

With respect to age, we found that activities targeting nursery-aged children differ from activities targeting other age-groups as the former cover a wide range of curricular subjects, but rarely computer science. Regarding the goal of the activities, young adults differ from the other age-groups in the sense that for the former the goal of the activity is mainly to increase awareness of various scientific topics, however, for the other age-groups all goals were equally important.

As for the experts, we have learned that when it comes to the goal of the activities, females are overrepresented when the activity is about attitude change and covers the curricular subjects of biology, chemistry and geography.

These findings contribute to a better understanding of the rarely researched dynamics between the design decisions and the goals of informal and non-formal science learning activities.

We need to, however, highlight that the herein introduced study reflects a snapshot of a potentially dynamic context, and thus, these findings may not still be valid in the future. Since we applied an intensity sampling method, the generalizability of our results is also slightly limited. Therefore, studying the herein revealed patterns on a wider sample would add to our knowledge on this matter. 
Additionally, as we indicated already, subsequent research is required to address whether males are generally overrepresented as informal and non-formal science learning experts or it is just a sampling bias in the introduced study.

Nonetheless, this study can serve as a base for comparison for future studies. Besides, the herein reveal tendencies might be used as indications for determining the need for supplementing activities or the adjustment of existing ones e.g. to increase girls' involvement or to design activities that better suit the anticipated audience. However, it is important to note, that given the nature of the study, the directions of the revealed associations cannot be determined, hence should be investigated in future studies.

The focus of the findings reported in this paper was the association between age, gender, the content and the goal of the activities that the respondents were part of. In our forthcoming publications and future plans, we intend to present a study on the content of the activities in relation to the goal of these activities; the challenges the experts are facing and their possible solutions; the experts' perception of engagement and the value of playfulness and fun during the activities; and a detailed introduction of the experts' background.

\section{ACKNOWLEDGEMENTS}

We are grateful to the anonymous experts for their participation in this study and all the consortium members of the COMnPLAY SCIENCE project who helped during the survey design and data collection process. Special thanks to Heather King and prof. Georgios Yannakakis for their practical help when writing the paper. This project has received funding from the European Union's Horizon 2020 research and innovation programme under grant agreement NO 787476. This paper reflects only the authors' views. The Research Executive Agency (REA) and the European Commission are not responsible for any use that may be made of the information it contains.

\section{REFERENCES}

[1] Allen, A., Campbell, P. B., Dierking, L. D., Flagg, B. N., Friedman, A. J., Garibay, C., Korn, R., Silverstein, G., \& Ucko, D.A. 2008. Framework for evaluating impacts of informal science education projects - Report from a National Science Foundation Workshop.

[2] Bandura, A. 1989. Social cognitive theory. Annals of child development. Six Theories of Child Development. R. Vasta, ed. JAI Press. 1-60.

[3] Bar-El, D., Zuckerman, O. 2016. Maketec: A Makerspace as a Third Place for Children. Tangible, Embedded and Embodied Interaction (2016), 380 385 .

[4] Blikstein, P. 2014. Digital Fabrication and 'Making' in Education The Democratization of Invention. FabLab. (2014). DOI:https://doi.org/10.14361/transcript.9783839423820.203.

[5] Christensen, R., Knezek, G. and Tyler-Wood, T. 2015. Alignment of Hands-on STEM Engagement Activities with Positive STEM Dispositions in Secondary School Students. Journal of Science Education and Technology. 24, 6 (2015), 898-909.

[6] Chu, S.L., Quek, F., Bhangaonkar, S., Ging, A.B. and Sridharamurthy, K. 2015. Making the maker: a means-to-an-ends approach to nurturing the maker mindset in elementary-aged children. International Journal of Child-Computer Interaction. 5, September (2015), 11-19.

[7] Doerschuk, P., Liu, J. and Mann, J. 2007. Pilot summer camps in computing for middle school girls. ACM SIGCSE Bulletin. 39, 3 (Jun. 2007), 4. DOI:https://doi.org/10.1145/1269900.1268789.

[8] Dreessen, K., Schepers, S. and Leen, D. 2016. From Hacking Things to Making Things. Rethinking making by supporting non-expert users in a FabLab. Interaction Design and Architecture(s). 30, (2016), 47-64.

[9] Durães, D.A. 2015. Gaming and Robotics to Transforming Learning Methodologies and Intelligent Systems for Technology Enhanced Learning. Advances in Intelligent Systems and Computing. T. Mascio, R.
Gennari, P. Vittorini, and F. De la Prieta, eds. Springer, Cham. 51-56. of gender differences in mathematics: A meta-analysis. Psychological Bulletin. $136, \quad 1 \quad$ (Jan. 2010), $103-127$. DOI:https://doi.org/10.1037/a0018053.

Eshach, H. 2007. Bridging In-school and Out-of-school Learning: Formal, Non-formal, and Infromal Education. Journal of Science Education and Technology. 16, 2 (2007), 171-190. DOI:https://doi.org/10.1007/s10956006-9027-1.

Falk, J.H., Dierking, L.D., Osborne, J., Wenger, M., Dawson, E. and Wong, B. 2015. Analyzing Science Education in the United Kingdom: Taking a System-Wide Approach. Science Education. 99, 1 (2015), 145-173. DOI:https://doi.org/10.1002/sce.21140.

Fan, W. and Williams, C.M. 2010. The effects of parental involvement on students' academic self-efficacy, engagement and intrinsic motivation. Educational Psychology. 30, 1 (Jan. 2010), 53-74. DOI:https://doi.org/10.1080/01443410903353302.

Golsteijn, C., van den Hoven, E., Frohlich, D. and Sellen, A. 2014. Hybrid crafting: towards an integrated practice of crafting with physical and digital components. Personal and Ubiquitous Computing. 18, 3 (Mar. 2014), 593611. DOI:https://doi.org/10.1007/s00779-013-0684-9.

] Grover, S. and Pea, R. 2013. Computational Thunking in K-12: A Review of the State of the Field. Educational Researcher. 1, (2013), 38-43. DOI:https://doi.org/10.3102/0013189X12463051.

Hyde, J.S. 2005. The gender similarities hypothesis. American

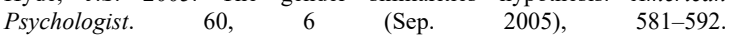
DOI:https://doi.org/10.1037/0003-066X.60.6.581.

Katterfeldt, E.-S., Dittert, N. and Schelhowe, H. 2015. Designing digital fabrication learning environments for Bildung: Implications from ten years of physical computing workshops. International Journal of ChildComputer Interaction. 5, (Sep. 2015), 3-10. DOI:https://doi.org/10.1016/j.ijcci.2015.08.001.

Lee, I., Martin, F., Denner, J., Coulter, B., Allan, W., Erickson, J., MalyinSmith, J. and Werner, L. 2011. Computational thinking for youth in practice. ACM Inroads.

] Lin, F.L., Wang, T.Y. and Yang, K.L. 2018. Description and evaluation of a large-scale project to facilitate student engagement in learning mathematics. Studies in Educational Evaluation. 58, December 2016 (2018), 178-186. DOI:https://doi.org/10.1016/j.stueduc.2018.03.001.

Linnenbrink, E.A. 2007. The Role of Affect in Student Learning. Emotion in Education. Elsevier. 107-124.

Litts, B.K. 2015. Resources, facilitation, and partnerships: three design considerations for youth makerspaces. Interaction Design and Children (2015), 347-350.

Mahoney, J.L., Larson, R.W., Eccles, J.S. and Lord, H. 2005. Organized activities as development contexts for children and adolescents. Organized activities as contexts of development: Extracurricular activities, afterschool and community programs (Jan. 2005), 3-22.

Malone, T.W. 1981. Toward a Theory of Intrinsically Instruction Motivating. Cognitive Science. 5, 4 (1981), 333-369. DOI:https://doi.org/10.1207/s15516709cog0504_2.

Malone, T.W. and Lepper, M.R. 1987. Making learning fun: A taxonomy of intrinsic motivations for learning. Aptitude learning and instruction.

McLean, M. and Harlow, D. 2017. Designing inclusive STEM activities: A comparison of playful interactive experiences across gender. Interaction Design and Children (2017), 567-574.

Moldovan, O. and Bocos-Bintintan, V. 2015. The necessity of reconsidering the concept of non-formal education. Procedia - Social and Behavioral Sciences. 209, (2015), 337-343. DOI:https://doi.org/10.1016/j.sbspro.2015.11.245.

Papavlasopoulou, S., Giannakos, M.N. and Jaccheri, L. 2017. Empirical Studies on the Maker Movement, a Promising Approach to Learning: A Literature Review Empirical studies on the Maker Movement , a promising approach to learning: A literature review. Entertainment Computing. 18, (2017), 57-78. DOI:https://doi.org/10.1016/j.entcom.2016.09.002.

Papavlasopoulou, S., Giannakos, M.N. and Jaccheri, L. 2019. Exploring children's learning experience in constructionism-based coding activities through design-based research. Computers in Human Behavior. (Jan. 2019). DOI:https://doi.org/10.1016/j.chb.2019.01.008. 
[29] Patton, M. 1990. Purposeful sampling. Qualitative evaluation and research methods. Sage. 169-186.

[30] Posch, I., Ogawa, H., Lindinger, C., Haring, R. and Hörtner, H. 2010. Introducing the FabLab as interactive exhibition space. Interaction Design and Children (2010), 254-257.

[31] Pucci, E.L. and Mulder, I. 2015. Star(t) to Shine: Unlocking Hidden Talents Through Sharing and Making. Distributed, Ambient, and Pervasive Interactions (2015), 85-96.

[32] Ryan, R.M. and Deci, E.L. 2000. Self-determination theory and the facilitation of intrinsic motivation. American Psychologist. 55, 1 (2000), 68-78. DOI:https://doi.org/10.1037/0003-066X.55.1.68.

[33] Ryan, R.M., Mims, V. and Koestner, R. 1983. Relation of reward contingency and interpersonal context to intrinsic motivation: A review and test using cognitive evaluation theory. Journal of Personality and $\begin{array}{lllll}\text { Social Psychology. } & 45, & 4 & \text { (1983), } & 736-750 .\end{array}$ DOI:https://doi.org/10.1037/0022-3514.45.4.736.

[34] Shernoff, D.J. and Csikszentmihalyi, M. 2006. Flow in Schools. Handbook of Positive Psychology in Schools. (2006), 131-146. DOI:https://doi.org/10.2307/1423345.

35] Sonnert, G., Fox, M.F. and Adkins, K. 2007. Undergraduate Women in Science and Engineering: Effects of Faculty, Fields, and Institutions Over Time. Social Science Quarterly. 88, 5 (Dec. 2007), 1333-1356. DOI:https://doi.org/10.1111/j.1540-6237.2007.00505.x.

[36] Telhan, O., Kafai, Y.B., Davis, R.L., Steele, K. and Adleberg, B.M. 2014 Connected messages: a maker approach to interactive community murals with youth. Interaction Design and Children (2014), 193-196.

[37] Trotman, A. 2017. Why don't European girls like science or technology?

[38] Witherspoon, E.B., Schunn, C.D., Higashi, R.M. and Baehr, E.C. 2016 Gender, interest, and prior experience shape opportunities to learn programming in robotics competitions. International Journal of STEM Education. 3, 1 (2016), 1-12. DOI:https://doi.org/10.1186/s40594-0160052-1.

[39] Women in STEM, Women in Computer Science: We're Looking at It Incorrectly: 2014. https://cacm.acm.org/blogs/blog-cacm/180850-womenin-stem-women-in-computer-science-were-looking-at-it-

incorrectly/fulltext. 